\title{
A STUDY ON CLOUD COMPUTING ADOPTION IN E-BUSINESS
}

\author{
H.S. Lim and Wahidah Husain \\ School of Computer Sciences, Universiti Sains Malaysia, 11800 Pulau Pinang, Malaysia \\ Email: wahidah@cs.usm.my
}

\begin{abstract}
Cloud computing is an undeniable shift paradigm due to the rapid advancement in processors, distributed grid computing, disk storage and performance, Internet networking and virtualization techniques. Adoption of cloud computing in business creates some considerable business values. So basically this paper will concentrate on the study of the cloud adoption in business. Besides, this paper also aims to investigate the business benefit gained by adopting cloud computing in the business as well as the key challenges of cloud adoption in business.
\end{abstract}

Keywords: Cloud Computing; E-business

\begin{abstract}
Abstrak
Cloud computing adalah sebuah bagian dari pergeseran paradigma yang disebabkan karena kemajuan pesat dalam prosesor, komputasi grid terdistribusi, penyimpanan disk dan kinerja, jaringan internet dan teknik virtualisasi. Adopsi cloud computing dalam bisnis menciptakan beberapa nilai-nilai bisnis yang cukup signifikan. Pada dasarnya, paper ini berkonsentrasi pada studi tentang adopsi cloud dalam bisnis. Selain itu, makalah ini juga bertujuan untuk menyelidiki manfaat bisnis yang diperoleh dengan mengadopsi cloud computing dalam bisnis serta tantangan utama adopsi cloud dalam bisnis.
\end{abstract}

Kata kunci: Cloud Computing; E-business

\section{Introduction}

Nowadays, many firms need to perform their business processes and operations in an outstanding manner in order to gain competitive advantages to stay in the business arena as well as to improve their business performance [1]. Traditionally, the early firms usually built their own server farms that specifically designed to meet peak demands by utilizing bundled of hardware and software alternatives. This direct implies that there are a number of fixed capital costs associated to those early firms, for example they need to invest a lot of capital cost to purchase the required hardware and software, and they are the one responsible to maintain the hardware and software [2]. In short, this was time consuming, capital intensive and relatively inflexible. However, all the related fixed capital cost can be reduced or eliminated by adopting cloud computing in their business.

Cloud computing is an undeniable shift paradigm due to the rapid advancement in processors, distributed grid computing, disk storage and performance, Internet networking and virtualization techniques. Adopting of cloud will be able to reduces fixed capital cost that required to be invested by a firm because it can reduce or eliminate the needs of buying costly hardware and software like what most firms have done previously. Cloud computing allows firms to utilize the services provided on the cloud as many as they need at any given time and they will be charged merely based on the resources that they used. In other word, it converts fixed capital costs into variable costs of a firm and offers profit maximization via the economies of scale [2].

Basically, the adoption of cloud computing is gradually gaining momentum in recent years as it provides high visibility and accessibility in which a firm can have productivity software alone and everything else would be from cloud. This phenomenon can be seen especially in those big companies that aim to sustain their business in a cost effective and efficient way. Besides, most of the services provided by the cloud are low cost and it is ubiquitous and readily available. So, indirectly it can create multilateral network effects among businesses and increase the productivity within business [3]. 
The Section 2 in this paper is about the related literature review for this research topic, for example the cloud computing definition, the three main primary service models of cloud computing: Software as a Service (SaaS), Platform as a Service (PaaS) and Infrastructure as a Service (IaaS), the deployment models and etc. Then in section 3 will further examine the current trend of cloud computing in the business world; the business value creation, business opportunity as well as the benefits gained by adopting cloud; and the last ones would be the key challenges of adopting cloud in the business. Finally, section 4 will conclude this paper.

\section{Literature Review}

Nowadays, cloud computing is one of the modern and complex research topic other than Big Data, Social media, and Mobility. There are some studies stated that the cloud computing is one of the technologies that will experience the most growth in recent years, occupying more than $12 \%$ of the IT market by 2015 [1][4]. Another study said that there are forecasts which estimate that the cloud service market's revenue will reach about $\$ 148.8$ billion by 2014 [2]. Besides, the financial crisis and recession have also contributed to the accelerating adoption of cloud computing as companies have been forced to find cost-effective IT solutions [2].

\subsection{What is cloud computing?}

Cloud computing started in the last decade as a result of the convergence of several earlier technologies and IT operating models. From technical point of view, cloud computing was enabled by a combination of virtualization, cluster computing, grid computing, broadband networking and large scale data centers centralized at low cost locations [2][5]. Distribution of resources and the on-demand provision and accessibility via networked environments have been the central characteristics of cloud computing [5]. Simply say, resources can be distributed physically across geographical locations or logically across servers. They are accessible within organization via intranet or outside of organization via Internet. Standard protocols facilitate communication over both intranet and internet networks.

The cloud computing definition that is most commonly and widely used is specified and managed by the United States National Institute of Standards and Technology (NIST) as: "Cloud computing is a model for enabling ubiquitous, convenient, on-demand network access to a shared pool of configurable computing resources (e.g. networks, servers, storage, applications, and services) that can be rapidly provisioned and released with minimal management effort or service provider interaction" [2][4][6].

There are a few essential characteristics of cloud that can be identified from the definition: distribution of resource or resource pooling, broad accessibility through the network, and on-demand provision [1][5]. In other words, the cloud contains a collection of easily usable and accessible virtualized resources (e.g. hardware, development platforms, and services); everything is treated as a service and can be accessed anytime anywhere. Then, these resources can be dynamically reconfigured to adjust to a variable scale, allowing for optimum resource utilization, meaning that a firm can scale up or down the cloud facility based of its business needs [7]. Furthermore, a firm only needs to pay for what facilities that being requested and used.

\subsection{Three Primary models of Cloud Computing}

The vision of "Everything as a Service" (XaaS) of the cloud application has been associated with many core services provided by the cloud service providers for example application, platform, web services, database, processes, and so forth [8]. A service model determines the type of computing resources to be offered to the consumers. Basically, there are several service models available of cloud but the commonly and widely used one is Platform as a Service (PaaS), Software as a Service $(\mathrm{SaaS})$ and Infrastructure as a Service (IaaS) [1][2][4][9].

1. Platform as a Service (PaaS)

It is the service model that provides a development environment and programming platform to the users [2]. Basically, the users can design, program, build and deploy their own applications onto the cloud by using the application framework, programming language, and built-in application programming interfaces (APIs) that is provided or supported by the cloud service provider. It embraces all the entire software development lifecycle process such as design, implementation, debugging, testing, deployment and operation.

2. Software as a Service (SaaS)

It is at the top of cloud infrastructure layer in which the capability provided to the end users is a set of integrated service of platform, hardware and applications that can accessed through web browser [2]. In short, software applications are offered as services by the provider. For example service provider that provided this type of service 
like Salesforce.com offering its CRM application as a service [9].

3. Infrastructure as a Service (IaaS)

It is the service model where IT infrastructure based on physical and virtual resources are offered as services to customers [2]. These resources meet the end user requirements in terms of processing power, storage, network, operating system and other hardware-related service. This enables many firms to rent the available resources rather than spending a huge of capital investment to purchase and maintain the required hardware such as high-end server.

Out of these three models, most of the firms like to outsource their internal IT functions by using IaaS and PaaS. Although majority firms view cloud as an alternative of outsourcing as the liability of resource management is shifted to the cloud service provider; however in fact each service model has its own degree of control.

\subsection{Three Main Models Cloud-based Environments}

The cloud can be classified into three possible cloud environments or deployment models and basically all the models share the common characteristic of cloud as mentioned above; resources distribution, accessibility through network and on-demand provision. The deployment models are private cloud, public cloud, hybrid cloud, and community cloud.

1. Private cloud - the cloud resources and services are owned by the firm and the accessibility is merely within the internal environment of the firm such as intranet [1][2][4]. This implies that the security level of private cloud is very high but also is the most expensive one.

2. Community cloud - it can be considered as the extended of private cloud just that the resources and services are shared among those specific firms that have common interests [2][5].

3. Public cloud - the cloud resources and services are made available to the public by the cloud service providers and basically the provider has the control over the resources [1][2][4]. The public cloud can be classified as the most insecure model but is also the cheapest one.

4. Hybrid cloud - It is a combination of two or more models of cloud-based environments that mentioned above which are bound together by a technology that enables data and application portability [1][2][4].
One interesting thing to notice that enterprises and large business are mainly the owners and users of private clouds, while public cloud are user by smaller businesses and millions of individual consumers [9].

\section{Analysis and Discussion}

\subsection{Impact of cloud computing in business world}

The impact of cloud computing is tremendous on both firms and their consumers. On consumer side, they are able to access all of their documents and data from any devices as long as they are connected to the Internet network. On the other side, firms will be able to rent the computing power and storage from a cloud service provider and pay on demand [10]. The scalability and flexibility of cloud computing service provision allows small firms to scale up or down to meet according to their business needs [2].

Other than that, the cloud computing has an indirect but substantial impact of promoting new business creation and on the macroeconomic performance of countries. Basically, adoption of cloud computing allows potential business entrants to save on the fixed costs associated with hardware and software and IT maintenance and administration cost, and then turns part of this capital expenditure into operative expenditure [9][10-12]. The cost savings especially for the huge up-front investment can encourage new business creation. This cost reduction of fixed costs of capital and operational expenditure which then creates a quick scalability and growth for a business as well as for a country.

There are some research stated that the diffusion of cloud can actually give a positive and substantial contribution to the annual growth rate and helping to create about millions of new jobs via the development of a few hundred thousand new small and medium-sized enterprises (SMEs) in European Union (EU) [2][11]. This impact which in turn can indirect boost the economy for a nation because a country's standard and economy is driven by the existing or new businesses performance and growth, the labour market conditions, and etc.

The size of fixed cost savings can be considered as the main key factor for determining the impact of cloud computing. According to International Data Corporation (IDC), the cost reduction can hit until about 50\% [11]. Besides, the IDC research indicates that worldwide revenue from public IT cloud services exceeded $\$ 40$ billion in 2012 and will reach $\$ 100$ billion in 2016 [13]. Furthermore, cloud also strongly 
correlated to other facets; include the expanding mobility of different devices and the mobile apps, Big data tools, and the growing availability of wireless broadband and social media network.

\subsection{Business Benefits of Adoption Cloud}

1. Cost reduction/savings

Cloud adoption in business can brings a massive cost reduction on the investment for hardware and software resources, reducing ongoing operational, upgrade and maintenance costs. [1-3][9][12]. The cost savings will be able to support an emerging company with a minimum investment in IT.

2. Scalability and flexibility

The cloud consumers can dynamically scale up and down or even turn off the cloud facilities and services according to their business requirements, demands, and needs [1][2][7][9][12].

3. Accessibility and mobility

The cloud provides a wider range of accessibility and mobility to access the resources and services provided by the cloud service provider [3][12].

4. Focus on the core business

The internal collaboration in a company can be increased and improved because of the capability to access to the cloud application and data at anytime, anywhere through different devices [2][3][12]. This will allow a business to adapt to market opportunities quickly.

5. Access to better IT resources

The cloud infrastructure is very powerful and able to lead to process efficiency to a business [2][12]. This condition can create a better internal coordination within an organization.

6. Reduce power consumption

Cloud has a little impact on environment facet because the improvement of energy efficiency may contribute to the reduction of total carbon emissions in a substantial way [3][11].

\subsection{Key Challenges of Adoption Cloud in Business}

1. Security

Most of the people are worrying about the security strength of the cloud when they are thinking to adopt cloud in their business [1],[9][12][13]. The concerns might include the control loss of the data, data information leak or exposure, security breaches, and so on.

\section{Knowledge}

The knowledge about cloud computing among people is another crucial aspect that hindering the maturity of cloud in business [2][3][7]. People with inadequate knowledge of cloud computing can cause misapplication of cloud in their business, lack of trust to adopt cloud in their business, and so forth.

3. Integration

This problem most likely occur when a company is trying to migration their legacy system onto the cloud [2][7][13]. The cost associated with this type of integration is extremely high and require intensive resources. However, the final result of this integration can create one unified interoperable system that have a better manage and control in terms of business process work flow, work quality, human resources and so on.

4. Cost

In practice, adoption of cloud in business can lead to a cost savings for a company. However, there is also some research stated that cost can be also one of the obstacles of adopting cloud [7][13]. The reasons might due to some of the people believe they can save more cost by adopting conventional methods to run their business instead of taking the cloud approach, lack of knowledge about cloud, and so on.

\section{Conclusion}

Cloud computing is a sophisticated technology evolving dramatically in recent years. It has a considerable value for business. A business can gain a lot of benefits/business values if the cloud is properly being implemented and integrated. One thing to be noted is that let business requirements leads you, not the hype. Without a proper understanding of cloud as well as the business needs might bring negative impact to the business Besides, security facet in cloud computing is the major obstacle that hindering the maturity and growth of the cloud in the business. There is a risk exists and clouds service providers have to put effort to secure personal and business data as well as provide committed level of reliability.

\section{References}

[1] Trigueros-Preciado, S., Pérez-González, D. \& Solana-González, P., "Cloud computing in industrial SMEs: identification of the 
barriers to its adoption and effects of its application In Electronic Markets”, 2013, pp. 1-10.

[2] Bayrak, E., Conley, J. P., \& Wilkie, S., "The Economics of Cloud Computing", The Korean Economic Review, 2011, pp. 203230.

[3] "The Business Impact of the Cloud", according to 460 Senior Financial DecisionMaker, March 2012.

[4] Phaphoom, N., Oza, N., Wang, X., \& Abrahamsson, P., "Does cloud computing deliver the promised benefits for IT industry?", in Proceedings of the WICSA/ECSA 2012 Companion Volume, New York, NY, USA, 2012, pp. 45-52.

[5] Géczy, P., Izumi, N., \& Hasida, K., "Cloudsourcing: Managing Cloud Adoption", Global Journal of Business Research, 2012, pp. 57-70.

[6] Mell, P., \& Grance, T., "The NIST definition of cloud computing", in NIST special publication, 2011. Bayrak, E., Conley, J. P., \& Wilkie, S., "The Economics of Cloud Computing", The Korean Economic Review, 2011, pp. 203-230.

[7] Masiyev, K.H.; Qasymov, I.; Bakhishova, V.; Bahri, M., "Cloud computing for business," in Application of Information and Communication Technologies (AICT), 2012 6th International Conference, 17-19 Oct. 2012, pp. 1-4.

[8] Tai, S., Nimis, J., Lenk, A., \& Klems, M., "Cloud Service Engineering", in Proceeding of the 32nd ACM/IEEE International Conference on Software EngineeringVolume 2, 2010, pp. 475-476.

[9] Motahari-Nezhad, H. R., Stephenson, B., \& Singhal, S., "Outsourcing business to cloud computing services: Opportunities and challenges". IEEE Internet Computing, Palo Alto, 2009.

[10] Zardari, S., \& Bahsoon, R., "Cloud Adoption: A Goal-Oriented Requirements Engineering Approach", in Proceedings of the 2nd International Workshop on Software Engineering for Cloud Computing, May 2011, pp. 29-35.

[11] E.Federico, "The economic consequences of the diffusion of cloud computing", the Global Information Technology Report 2010, 2009, pp. 107-112.

[12] Armbrust, M., Fox, A., Griffith, R., Joseph, A. D., Katz, R., et al., "A view of cloud computing". Communication of the ACM 53(4), April 2010, pp. 50-58.

[13] "Analysis: Cloud Computing." Public CIO, 2009 Business Source Complete. [Accessed: 21 May 2013] 